\title{
The Childcare Center: How to Ensure Quality Childcare Practices
}

\author{
Zahyah Hanafi ${ }^{1}$ \\ ${ }^{1}$ College of Arts and Sciences, School of Education and Modern Languages, Universiti Utara Malaysia, Sintok, \\ Kedah, Malaysia \\ Correspondence: Zahyah Hanafi, College of Arts and Sciences, School of Education and Modern Languages, \\ Universiti Utara Malaysia, 06010 Sintok, Kedah, Malaysia. E-mail: zahyah20022@yahoo.com
}

Received: June 21, 2015 Accepted: October 13, 2015 Online Published: October 26, 2015

doi:10.5539/ass.v11n25p90 URL: http://dx.doi.org/10.5539/ass.v11n25p90

\begin{abstract}
Ensuring staff display best practices when handling children at childcare center is a task that requires the management to consistently instill knowledge and skills on child development. This paper will unfold the initiative of a childcare manager who believes that in order to ensure the center provides best services to the children, a research into the level of knowledge and skill on handling children is necessary. Thus, a case study was conducted to identify the key areas of a quality childcare center: staff relationships with children and peers, partnerships with families, programming and evaluation, children's experiences and learning, protective care and safety, health, nutrition and wellbeing, and managing to support quality. A questionnaire which was adapted from the Quality Improvement Accreditation System (QIAS) model was administered to all the staff at the center. The results revealed that there are areas that reflect staff ability to implement what was taught. However, there are areas that need further training and guidance and there are also areas that urgently require consistent training and monitoring. The paper ends with discussion between the researcher and the manager on ways to enhance staff development.
\end{abstract}

Keywords: quality improvement accreditation system (QIAS), childcare center management, quality childcare

\section{Introduction}

Research into quality of childcare center is seen as a requisite demand if practitioners and policy makers intend to ensure children are provided with a healthy environment to develop their potentials, well-being and learning. It is also accepted as a means to improve early childhood provision for the future (Sylva, Siraj-Blatchford, Taggart, Sammons, Melhuish, Elliot, \& Totsika, 2006). These believes were supported by arguments that when childcare providers implement quality practices in their center, it is likely to enhance children's cognitive, social (Burchinal \& Cryer, 2003) and academic development (Ishimine, 2010), increases their emotional and social skills (Landry et al., 2013), and helps children to be more social and positively engaged with their peers (Vandell, 2004). It also helps to provide a foundation for their school success (Shonkoff \& Phillips, 2000), establish a basis for skill acquisition later in their life (Heckman, 2006) decreases children's anxiety and they are less likely to be placed in special education classes (Committee for Economic Development, 2006). Generally, these positive outcomes were linked to better quality programs (Love et al., 2003; Peisner-Feinberg et al., 2001; Sims, Guilfoyle, \& Parry, 2005), quality teacher-child interactions (Kontos \& Wilcox-Herzog, 1997); qualified early childhood teachers (Children's Services Regulations, DEECD, 2009) and teacher leadership (Sammors et al., 2002; Sylva et al., 2003). Thus, it can be argued that when childcare centers provide quality services to the children this will lead to less negative behavior and even eliminate social incompetency (Howes, Phillipis, \& Whitebook, 1992). Therefore, this study takes the first step to investigate whether the manager and the childcare providers are implementing the best practices at their center. Thus, the objective of this study is to identify the level of quality childcare practices in the childcare center under investigation. Identifying which of the quality areas are high, average or low is the main concern of this study. The findings of this study will be a guide to define and measure quality childcare practices by childcare providers in the center, an indicator to the strength and weakness prevalent in the childcare program that is currently used, and a source of reference to create in-house training and professional development for the staff.

\subsection{Quality Childcare Center}

Quality in childcare is generally accepted as having two dimensions - structural quality (e.g. childcare provider's 
level of education, experience and specialized training/qualifications, number of children and childcare providers in the center) and process quality (e.g. provider - child interaction, language stimulation and the extent to which relationships between childcare providers and children are warm and supportive) (NICHD ECCRN, 2000). These dimensions were found to be significant aspects in childcare quality that strength in one dimension is regarded as insufficient to foster children's overall development. However, for the purpose of this study, the process quality will be the area of concern as it will help to answer the objective of this study.

Effective management is needed in every childcare center to attain the desired goals with the least expenditure of time, energy and money. Whether the operation is an agency, school, business, or family, whether it is operated for profit or as a nonprofit basis, management is needed. One approach to assess quality management of early childcare center that has gained increasing popularity in Australia is The Quality Improvement and Accreditation System (QIAS). This instrument is used to assess the quality process of children's experiences during their stay at the center. The instrument covers the following quality areas: staff relationships with children and peers, partnerships with families, programming and evaluation, children's experiences and learning, protective care and safety, health, nutrition and well-being, and managing to support quality.

\section{Research Methods}

This is a case study of a childcare center. This study combines both quantitative and qualitative methods. Analysis quantitative data using Statistical Package for the Social Science (SPSS) version 16 was used to obtain the mean descriptive for the level of quality management practices in the childcare center under study. Interview further supported the findings of the quantitative data. The study adopted the mixed methods approach as it is believed that investigating into the quality of the childcare practices using both methods would provide a clearer picture of what the management has implemented and how much has been internalized and practiced by the childcare providers. Thus, the findings from both methods rather than one alone, offer a stronger platform to inform the management on the strength and weakness of the current practices at the center. The childcare providers responded to the questionnaire while the manager was interviewed on her management practices.

QIAS is used to gauge childcare centers in Australia and it has been reported that the Australia Quality Improvement and Accreditation System (QIAS) has a higher standard of quality in formal childcare services than those reported for US and UK (Harrison, 2008).

\subsection{Sampling}

The childcare center is situated in an urban area, run by a manager, seven childcare providers and a cook. The minimum qualification of the childcare providers is high school certificate (SPM). Their qualification varies from high school to degree holders. On the whole the center provides childcare services to 41 children, aged 2 months to 4.5 years old.

\subsection{Instrument}

The Quality Improvement and Accreditation System (QIAS) was used to assess the quality process of the children's experiences during their stay at the center. The QIAS items were adapted to fit into the Malaysian context. The items covered the following quality areas:

- Quality Area 1: staff relationships with children and peers (10 items);

- Quality Area 2: partnerships with families (4 items);

- Quality Area 3: programming and evaluation (4 items);

- Quality Area 4: children's experiences and learning (10 items);

- Quality Area 5: protective care and safety (6 items);

- Quality Area 6: health, nutrition and well-being (8 items) and;

- Quality Area 7: managing to support quality (5 items).

QIAS ratings for each quality area ranged from a score of $1=$ unsatisfactory, $2=$ satisfactory, $3=$ good quality, 4 $=$ high quality. However, for this study the scale was adjusted to: $1=$ unsatisfactory, 2 = least satisfactory, $3=$ satisfactory, $4=$ highly satisfactory, to enable the childcare providers a more comprehensible understanding of the scale. Quality area scores were combined to form an average QIAS score for each quality area. The overall quality area ranged from average to high: $1.00-2.50=$ low, $2.51-3.50=$ average and $3.51-4.00=$ high. The instrument reliability was high, ranging from $0.84-0.94$. 


\section{Results}

Table 1 presents ranking of the quality areas according to the mean for each quality area. Based on the analysis it was reported that the overall level of quality practices for the center was high (mean=3.68). Quality Area 6, 5, 7, 4, 2 and 1 were rated high except for Quality Area 3 which was rated average (mean=3.46).

Table 1 . Ranking of quality areas

\begin{tabular}{lll}
\hline Quality Area & No. of Item & Mean Value \\
\hline Quality Area 6: Health, Nutrition and Wellbeing & 8 & 3.79 \\
Quality Area 5: Protective Care and Safety & 6 & 3.76 \\
Quality Area 7: Managing to Support Quality & 5 & 3.74 \\
Quality Area 4: Children's Experiences and Learning & 10 & 3.71 \\
Quality Area 2: Partnerships with Families & 4 & 3.68 \\
Quality Area 1: Staff Relationships with Children & 7 & 3.67 \\
Staff Relationships with Peers & 3 & 3.43 \\
Quality Area 3: Programming and Evaluation & 4 & 3.46 \\
Level of quality practices & & 3.68 \\
\hline
\end{tabular}

Ranking scale: $1.00-2.50=$ low, $2.51-3.50=$ average, $3.51-4.00=$ high

\subsection{Quality Area 1: Staff Relationships with Children and Peers}

The staff relationships with children and peers were combined but for this study we decided to separate it into two sub-areas: Staff relationships with children and Staff relationships with peers so that we can gauge the level of specific relationships (Table 1). There were 7 items to assess the childcare providers' understanding of their relationship with children:

1. Staffs create interaction with children in a warm and friendly way. $(3.57=$ high);

2. Staffs guide children's behavior in a positive way. $(3.57=$ high $)$;

3. Staffs initiate respectful communication with each child. $(3.71=$ high $)$;

4. Staffs maintain respectful communication with each child. $(3.71=$ high);

5. Staffs respect each child's family background. $(3.86=$ high $)$;

6. Staffs respect each child's ability. $(4.00=$ high $)$;

7. Staffs treat all children equally. $(3.29=$ average $)$.

The overall mean for Quality Area 1 in terms of the staff relationships with children and peers was high (mean=3.60). However, when the relationship was split between children and peers, the rating was different. Staff Relationships with Children was high (mean= 3.67) while Staff Relationships with Peers was just average $(m e a n=3.43)$. The high rating for staff relationships with children reflects that the childcare providers believed that they have close relationship with the children at the center. All items were rated high except item 7 which was rated average (mean $=3.29$ ). In-spite of high ratings for all items the childcare providers still believed that they have not treated the children at the center equally.

During the interview with the Manager, this was her response to the question on staff relationships with children:

Do you think staff relationships with children are important? (Researcher)

...in order for children to learn, they need to be able to have really good ... they need to build that bond...that positive attachment with their carers...because if they don't then they don't feel safe, they don't have that good relationship... they won't be able to explore further...there won't be bonding... Bowbly's theory of attachment... (Manager)

How do you build your staff relationship with children? (Researcher)

...we encourage bonding between carers and children ... not just through the activities ...its actually operational... you need to have that special time with the children... For example, when children first start... there's the settling period...one practitioner will be assigned to the child... with the parents around, slowly they get to know each other, use to each other and so on... (Manager) 
Relationships will only develop when there are interactions between childcare providers and the children. This interaction may take the form of consistent inter-personal communication between the childcare providers and the children in the center and this in turn will develop mutual understanding between them (Liu-Yan \& Pan, 2008). During this interaction childcare providers may offer emotional support, reciprocal communication, and cognitive stimulation which may act as scaffolding to enhance the child's learning (Ainsworth et al., 1978; Olson, Bates, \& Bayles, 1984). Thus, the findings reflect that both the childcare providers and their manager seemed to agree that it is important to create a strong relationship with the children.

Staff Relationships with Peers: There were 3 items to assess the childcare providers' understanding of their relationship with peers:

1. Staffs communicate effectively among themselves to promote respect $(3.29=$ average $)$;

2. Staffs communicate effectively among themselves to promote professional teamwork $(3.57=$ high $)$;

3. Staffs create a healthy working environment to promote understanding among themselves $(3.43=$ average $)$ '

The mean for the relationship between staff and peers was 3.43 (Table 1), reflecting that the childcare providers believed that their relationship with their peers was just average. Item 2 was rated high while items 1 and 3 were rated average. When interviewed, the Manager has this to say on the issue:

... I encourage them to be open... I be their psychologist ...

...we always have briefing...I want the staff to know what's happening ... parents saying this...asking their opinion, how can we make it happen...yes... it's important they have close relationships with each other... so they can work together, help each other... (Manager)

The Manager believed staff relationships with peers is important and she has initiated several ways to ensure the relationship between the childcare providers is healthy. However, this was not what the childcare providers perceived. They felt their relationship was just average. Therefore, this is the aspect that the Manager needs to deal with.

\subsection{Quality Area 2: Partnerships with Families}

Based on the findings, the overall mean for Quality Area 2 was high with a mean of 3.68 (Table 1), reflecting that the childcare providers created very healthy partnership with families. However, less was done in terms effectively exchanging information about the center (mean $3.43=$ average). This quality area was assessed using 4 items:

1. Staffs in the center have an orientation process for children and parents. $(4.00=$ high $)$

2. Staffs and parents communicate effectively to exchange information about the child.(3.71= high)

3. Staffs encouraged family participation and involvement in the center. $(3.57=\mathrm{high})$

4. Staffs and parents communicate effectively to exchange information about the center. $(3.43=$ average)

This strong partnership with families could have been achieved through efforts made by the Manager. The interview revealed:

That relationship is important especially when they're settling in... children are actually observing how we are interacting with their parents and if they see parents are trusting us they will have that trust in us too... that is why that is a sensitive period during the settling in...if this does not happen then the children will take a longer time to settle in... (Manager)

And also information from the parents is important so that we can give the right care for their children and also if there are little issues at all...its so important to handle it right... (Manager)

Having the relationship is where I can call them and talk heart to heart on what I'm doing and from there I'll find out whether they're happy and so on... and also supporting the parents for example in terms of information... support or anything that we can do (Manager)

Generally, staff and parents have similar goals and outcomes for the children. Thus, creating a strong partnership will benefit both parties. This partnership developed through active communication and consultation between childcare providers and parents. Studies have reported that when mothers and childcare provider consistently communicate this may increase interactions between childcare provider and the child, as well as between mother and child (Owen, Ware, \& Barfoot, 2000). Others have stressed that such partnerships are vital to the child's well-being, development and progress (QIAS Quality Practices Guide, 2005), linked to the child's developing more positive socialization skills (Rentzou, 2011) and this communication was found to be the single factor that 
helps to increase parent and community involvement in children's education (Magelky, 1990).

Thus, the findings revealed that both the manager and the childcare providers had done well in ensuring that strong partnership exists between them and the parents.

\subsection{Quality Area 3: Programming and Evaluation}

Based on the findings, the overall mean for Quality Area 3 was 3.46 (Table 1), reflecting the level of perception of the childcare providers towards their program and evaluation was just average. The childcare providers' believe that the program did not reflect much of the center's vision and mission and it did not really nurture each child into a successful learner. In addition, there was not much emphasis on documenting the child's learning. This quality area was assessed using 4 items:

1. The staffs take the child's progress into consideration when planning the program at the center. $(3.71=$ high $)$

2. The early childcare program reflects a clear statement of the center's vision and mission. ( $3.43=$ average $)$

3. Each child's learning is documented. $(3.43=$ average $)$

4. The program nurtures each child to be a successful learner. (3.29= average)

During the interview the Manager has this to say about her center's program and evaluation:

Basically, our program is learning through play. However, the day to day we teach will basically be set... activities will be based on six area of learning...the personal social emotional, the cognitive, knowledgeable understanding development and so on.

... we have planning meeting so the teachers will give their opinion in terms of what activities that we think is suitable. Once the topic is finished, we will have another meeting and... will... evaluate how well it went.

The childcare curriculum plays an important role in children's development. High-quality programs leaves positive effects on children's brain development especially in language skills and also provide the basis for future school success (Shonkoff \& Phillips, 2000) and this in turn instill in children a sense of perseverance and motivation in their life (Heckman, 2006). Similarly, assessment is a tool necessary to gauge the progress of the child. Through assessment childcare providers and parents will be informed of the child's progress at the center (Korjenevitch, 2010) and this is where improvements can be made.

Thus, the findings revealed that the childcare providers did not receive well the tasks performed by the Manager on this respect. Therefore, this is an area that the Manager needs to focus on to ensure whatever she does is being comprehend well.

\subsection{Quality Area 4: Children's Experiences and Learning}

Based on the findings, the overall mean for Quality Area 4 was 3.71 (Table 1) reflecting the level of perception of the childcare providers towards children's experiences and learning was high. All the items were rated high except for item 1 where the childcare providers were less encouraging towards each child making their own choices during activities (mean $3.43=$ average). This quality area was assessed using 10 items:

1. Staffs encourage each child to make their own choices during activities. $(3.43=$ average);

2. Staffs encourage each child to participate during activities. $(3.71=$ high $)$;

3. Staffs encourage each child to develop healthy relationship with peers. $(3.71=$ high);

4. Staffs encourage each child to maintain healthy relationship with peers. $(3.86=$ high);

5. Staffs promote each child's language and literacy abilities. (3.71= high);

6. Staffs promote each child's problem solving skills. $(3.57=$ high);

7. Staffs promote each child's mathematical abilities. $(3.71=$ high);

8. Staffs encourage each child's to enjoy in the expressive arts activities. ( $3.86=$ high);

9. Staffs promote each child's participation in the expressive arts. $(3.71=$ high);

10. Staffs promote each child's participation in physical activities. (3.86=high).

During the interview with the Manager her statements on "Staffs encourage each child to make their own choices during activities" seemed to contradict those made by the childcare providers:

Good practice is about allowing the children to choose activities and encouraging them

to join the activities. If they cannot or don't want to join the activities, its ok, they can 
choose another one, right. Because ... that activity is very boring for them...

...for them to understand the concept of sharing... effect on their relationship whether

they can play together or not. We have lots of ready, steady, go games, turn turning and

things like that... sometimes we talk about who is your best friend, why do you like to be

your friend...

...there are times for free play as well... During the free play, they are allowed to choose whatever they like or given the options. Normally, err... what I encourage my staff to do is actually to give them choices.. (Manager)

The childcare center should be a place filled with rich resources such as educational materials and equipment so as to allow children the opportunity to explore and discover while handling them. In addition, they should be allowed to play, interact with peers as well as adults in the center so as to enable them to learn social skills, increase their language proficiency, share ideas and relationships (QIAS Report, 2008, p. 37). Therefore, childcare centers should create programs that will enrich children's experiences and learning while being at the center.

Liu-Yan and Pan (2008) also stressed the role of 'physical environment' in the childcare center. Thus, it is a necessity to create learning corners and play materials to allow children to have the opportunity to be involved in active play and learning. Such an environment tends to develop children's cognitive competency (Vandell, 2004), have positive engagement with peers and less likely to have negative peer interaction (Holloway \& Reichart-Erickson, 1989; Wishard, Shivers, Howes, \& Ritchie, 2003). When staffs do not encourage each child to make their own choices during activities this may limit the child's ability to develop new experiences and learning. This was seen in Chilean preschool children where the schools still practices traditional approach in handling children: teachers still dictate the activities and the materials for the children (Herrera et al., 2005).

Thus, the findings revealed that at times what is being taught and conveyed in discussion by the Manager may not perceived clearly and comprehended by the staffs. Therefore, consistent monitoring and observation need to be done by the Manager so as to ensure what is being taught is well perceived and is seen being implemented.

\subsection{Quality Area 5: Protective Care and Safety}

The results showed that the overall mean for Quality Area 5 was 3.76 (Table 1), reflecting the level of perception of the childcare providers towards protective care and safety at the center was high. This area was rated second highest among the 7 quality areas. Even though the childcare providers believed protective care and safety at the center to be high but these aspects were concerning the children, the building and the equipment only. However, they felt the center did not do much in terms of promoting staff occupational health and safety procedures (mean $3.29=$ average). This quality area was assessed using 6 items:

1. Staffs act to protect each child $(4.00=$ high);

2. Staffs supervise each child at all times $(3.71=$ high);

3. Staffs ensure that potentially dangerous equipment, plants and objects are inaccessible to children $(4.00=$ high);

4. The center ensures that buildings are safe $(3.86=$ high $)$;

5. The center ensures all equipment is safe $(3.71=$ high);

6. The center promotes staffs' occupational health and safety procedures (3.29= average).

During the interview with the Manager this was what she said about child care and safety:

...they're climbing stairs ... making sure that there ... need to be somebody there. Not

to actually helping them because they need to have that independence, they need to be able to do it themselves, but making sure that they are safe and if there is anything that

they need, they can quickly act...

... and also when anybody is coming to pick the children and so on ... if it's a

stranger they don't allow that and they normally would call the parents because

we have a set of procedure for that...

In terms of staff:

...referring to new employees to get references from their previous employers... 
so that, you know, the person who is working here... from a good background.

\section{Well.. actually again we have policy about not allowing strangers into the center (Manager)}

Protective care and safety of the children should always be the concern of the Manager, childcare providers and families (QIAS, 2008). Therefore, it is important that childcare providers believed that it is their responsibility to ensure the children under their care be protected against injuries and accidents (Lewis, DiLillo, \& Peterson, 2004; Morrongiello, 2008). However, most childcare centers tend to overlook the occupational health and safety issues of their childcare providers. Even though there are few studies that looked into the health and safety of childcare providers but that do not mean it is less important compared to the health and safety of children. If childcare providers experience health and safety hazards in the childcare center, this will have serious health effects on the children under their care. The National Health and Safety Performance Standards for Out-of-Home Child-Care Programs manual (1992) listed the following occupational health and safety risks to child-care providers: 16 specific diseases, 7 stressors, and 4 environmental hazards.

Thus, the findings revealed that the Manager and the staff are highly sensitive to the issue on child care and safety. The safety procedures and rules set in the center have been well comprehended by the staff and implemented in their daily practices.

\subsection{Quality Area 6: Health, Nutrition and Wellbeing}

Based on the findings, the overall mean for Quality Area 6 was 3.79 (Table 1), reflecting the level of perception of the childcare providers toward health, nutrition and wellbeing of the children at the center was high. In fact, this area was rated the highest among the 7 quality areas. This quality area was assessed using 8 items:

1. Staffs promote healthy eating habits. $(3.86=$ high);

2. Staffs implement effective food safety practices. $(3.86=$ high $)$;

3. Staffs carry out effective hygiene practices. $(3.71=$ high);

4. Staffs encourage children to follow simple rules of hygiene. $(3.86=$ high $)$;

5. Staffs support each child's needs for rest, sleep and comfort. $(3.71=$ high);

6. The center acts to control the spread of infectious diseases. $(4.00=$ high $)$;

7. The center acts to maintain children's records of immunizations. $(3.57=$ high $)$;

8. Staffs ensure toileting and nappy changing procedures for children are positive experiences. $(3.71=$ high).

During the interview, the Manager stressed:

...well, we actually have a very good food menu here and you know, at one point, I even serve yogurt to the children. What we provide the children is actually a healthy balance meal with fruit and bread, and milk and things like that.

....so, when the children arrived in morning... we check the baby temperature... if their temperature is high, then, they are not allowed to stay at the center.

And we have our in-house-training about hygiene and transmitted diseases and things like that.

We had the Health Department... we asked them to come to check our place. We asked JKM to come as well to give us advice ... before eating, they have to, err... wash their hands and after going to the toilet. And also lining up waiting for their turn, eating... finishing their food and so on. These are all healthy habits.

Managers as well as childcare providers' knowledge and beliefs on heath, nutrition and well-being plays a vital role in ensuring children stay healthy and happy at the center. There are providers who believed that inculcating healthy eating habits and instilling positive and healthy behavior at mealtimes are among their responsibilities (Moore et al., 2005; Pagnini, Wilkenfeld, Ling, Booth, \& Booth, 2007). Such beliefs will have positif impact on children's well-being.

Children will spend hours at the center, from the time the parents drop them on the way to work and fetch them on the way home from work. Lack of knowledge on the effects of overeating and consuming unhealthy food may have negative impact on childhood dietary habits (Mikkelsen \& Chehimi, 2007).

The findings revealed a healthy center with the Manager and staffs ensuring the children fed with nutrious diet which in turn kept the children healthy and happy.

\subsection{Quality Area 7: Managing To Support Quality}

Based on the findings, the overall mean for Quality Area 7 was 3.74 (Table 1), reflecting the level of perception 
of the childcare providers towards managing to support quality at the center was high. This quality area was assessed using 5 items:

1. Written information about the center's management is available to families $(3.86=\mathrm{high})$;

2. Written information about the center's management is available for staff $(3.57=$ high $)$;

3. Staff policies facilitate continuity of care for each child easier $(3.86=$ high);

4. Staff practices facilitate continuity of care for each child easier $(3.86=$ high $)$;

5. Management provides professional development opportunities for all staff $(3.57=$ high $)$.

According to the Manager there are policies to cover the children:

We have policies on ... managing children behavior. We have policy on admission, policy on sickness, policy on administration of medication...

In terms of staff the Manager has the following procedures:

... on the first day of report for duty... normally, I spent the time with them, you know, talking with them to make them understand about policy and so on.

Staffs are recruited majority of the time ... through word of mouth. We give the interview ... and then, they are given trial day... and if they are seen to be suitable... they will be accepted. And we will ask the references from their ex-employers. Yes, that's what we do it. And also it's basically from others, other colleagues too.

The Manager stressed on the importance of staffs attending courses:

...definitely... they attend a lot of courses on early childcare... actually mathematical problem solving... which is like for 3 days and there's lots of other courses. ...well, training, exposure and... in-house-training-and also role model.

Studies have reported that childcare training and education is among the best predictor of quality center. Those with ECE certificate, diploma or degree tend to be more sensitive and responsive during interactions with children (Scarr et al., 1994), specific skill workshops are effective in enhancing childcare skills while those with degree in ECE was found to be the best predictor of overall classroom quality rating (Burchinal, Cryer, Clifford, \& Howes, 2002) and task persistence and cooperation among children (GAO report, 1998).

The findings revealed that the Manager believed that her staffs need to attend courses and in-house-training to ensure the center provides quality services. This is clearly perceived by the staffs as the practices that will ensure their center provides quality services to the children.

\section{Discussion and Recommendation}

The findings reported that the center has high quality overall practices (mean 3.68). However, when examined individual quality area it was found that 6 quality areas were rated high and 1 area, Quality Area 3: Programming and Evaluation was rated average (mean 3.46) by the childcare providers. Even though 6 areas were rated high but that does not mean this center is above average in terms of quality. For a center to be accredited as "quality" it should have high quality practices in all the identified quality areas. Therefore, the management should examine carefully each quality area by referring to the mean of each item in each quality area. This would clearly reflect the specific practice of the childcare providers that needed attention so that planning can be done to ensure the center can sustain or seek to achieve higher ratings so as to hit the 4.00 mean mark. The following are the areas that were ranked average and the manager and the researcher discussed ways to improve these areas. Below are the summary of the suggestions made.

Quality Area 1: Staff Relationships with Children and Peers: the following are the specific areas that need to be improved. In order to ensure staff treats all children equally (mean $=3.29=$ average) the manager realized there is a need to instill awareness in the staff of the positive effects of ensuring that equal treatment of children irrespective of their parents' socio-economic status, the child's physic, and development. Some of the positive outcomes would be: when the childcare provider responds immediately to a child's need this will build trusts and promotes cooperation between the child and the care provider (Ainsworth et al., 1978), responsive care providers helps children to foster closer relationship with their care giver and this in turn may reduce behavioral and emotional problems (Landry et al., 2013).

To ensure staff communicate effectively among themselves to promote respect $(3.29=$ average $)$ as well as staff create a healthy working environment to promote understanding among themselves. $(3.43=$ average $)$, the manager decides to increase activities in the center that will require teamwork and joint decision making. In 
addition, there should be a more open and transparent discussion on particular classroom challenges as this may promote collaborative behavior among the childcare providers and leads to improving the quality of their practices.

Quality Area 2: Partnerships with Families: the following areas needed improvement. In order for staff and parents to communicate effectively to exchange information about the center $(3.43=$ average), the manager decides that each childcare provider finds time for conversation with parents either in the morning when parents drop their child at the center or in the evening when parents fetch their child home. These sessions should focus on shared experiences, meaningful conversation about the activities, program and progress of the child. This is an important aspect of staff-parent relationship as through this exchange parents will be informed on matters pertaining to the program, activities and the mission and vision of the center. This in turn will allow parents to know, understand and plan so that they can participate with the happenings at the center. In addition, they are also aware of the initiative and planning by the management so as to ensure their children will be getting the best services.

Quality Area 3: Programming and Evaluation: the following are the areas of concern that needs to be improved.

1. The early childcare program reflects a clear statement of the center's vision and mission. $(3.43=$ average $)$

2. Each child's learning is documented. $(3.43=$ average $)$

3. The program nurtures each child to be a successful learner. (3.29= average)

The center has its own vision and mission however, it was not displayed nor disseminate to the staff. As such, the manager will ensure every staff and parent be given a copy of the center's vision and mission. In addition, a copy will be framed on the wall in the childcare center that will be easily viewed. As for documenting each child's learning, this exercise needs to be fully implemented at the center. Currently the center does have evaluation forms on documenting each child's progress but it was not done on a regular basis. Therefore, there is a need to conduct in-house training on the process of documenting children's progress in learning. There is also a need to examine the program again and ensure the center's mission and vision is clearly spelt clearly in the program. Finally, the program must have elements to nurture each child to be a successful learner.

Quality Area 4: Children's Experiences and Learning: the area that needs to be improve is on how to ensure staff encourage each child to make their own choices during activities $(3.43=$ average). According to the manager (during the interview), this aspect was clearly told to the childcare providers that they have to allow the children the opportunity to make choices during their activities. Therefore, there is a need to stress the importance of allowing the children to make their own choices during activities instead of dictating things to them.

Quality Area 5: Protective Care and Safety: the center seemed to overlook this aspect - staff's occupational health and safety procedures $(3.29=$ average $)$. Health promotion strategies are necesasry if the childcare providers are to be healthy role models for young children. The manager will ensure that the staff attend health and safety training as well as intervention workshop as these will have an effect not only on the children but also on themselves. They should be informed of the risk of infectious diseases when exposed to ill children.

\section{References}

Ainsworth, M., Blehar, M., Waters, E., \& Wall, S. (1978). Patterns of attachment. Hillsdale, N.J.: Erlbaum.

Burchinal, M. R., \& Cryer, D. (2003). Diversity, child care quality and developmental outcomes. Early Childhood Research Quarterly, 18, 401-426. http://dx.doi.org/10.1016/j.ecresq.2003.09.003

Burchinal, M. R., Cryer, D., Clifford, R. M., \& Howes, C. (2002). Caregiver training and classroom quality in childcare centers. Applied Developmental Science, 6(1), 2-11. http://dx.doi.org/10.1207/S1532480XADS 0601_01

Children's Services Regulations. (2009). S.R. No. 53/2009.

Committee for Economic Development. (2006). The economic promise of investing in high-quality preschool: Using early education to improve the growth and the fiscal sustainability of states and the nation. Washington, DC: Committee for Economic Development.

GAO Report. (1998).

Harrison, L. J. (2008). Does child care quality matter? Family Matters, 79, 14-25.

Heckman, J. J. (2006). Investing in disadvantaged young children is an economically efficient policy. Paper presented at the Forum on Building the Economic Case for Investments in Preschool. Retrieved from $\mathrm{http} / /$ www.ced.org/docs/report/report_2006prek_heckman.pdf 
Herrera, M. O., Mathiesen, M. E., Merino, J. M., \& Recart, I. (2005). Learning contexts for young children in Chile: Process quality assessment in preschool centers. International Journal of Early Years Education, 13(1), 13-27. http://dx.doi.org/10.1080/09669760500048253

Holoway, S., \& Reichert-Erickson, M. (1989). Child care quality, family structure, and maternal expectations: Relationship to preschol children's per elations. Journal of Aplied DevelopmentalPsychology, 10, 281-298. http://dx.doi.org/10.1016/0193-3973(89)90031-2

Howes, C., Phillips, D. A., \& Whitebook, M. (1992). Teacher characteristics and effective teaching in child care: Findings from the National Child Care Staffing Study. Child and Youth Care Forum, 21, 399-414. http://dx.doi.org/10.1007/BF00757371

Ishimine, K., Wilson, R., \& Evans, D. (2010). Quality of Australian childcare and children's social skills. International Journal of Early Years Education, 18(2), 159-175. http://dx.doi.org/10.1080/09669760.2010. 494430

Kontos, S., \& Wilcox-Herzog, A. (1997). Research in review: Teachers' interactions with children: Why are they so important? Young Children, 52(2), 4-12.

Korjenevitch, M., \& Dunifon, R. (2010). Child care center quality and child development. New York: Cornell University.

Landry, S. H., Zucker, T. A., Taylor, H. B., Swank, P. R., Williams, J. M., Assel, M., ..., Klein, A. (2013). Enhancing early child care quality and learning for toddlers at risk: The responsive early childhood program. Developmental Psychology, 50(2), 526-541. http://dx.doi.org/10.1037/a0033494

Lewis, T., DiLillo, D., \& Peterson, L. (2004). Parental beliefs regarding developmental benefits of childhood injuries. American Journal of Health \& Behavior, 28, S61-S68. http://dx.doi.org/10.5993/AJHB.28.s1.7

Liu, Y., \& Pan, Y. J. (2008). Development and validation of kindergarten environment rating scale. International Journal of Early Years Education, 16(2), 101-114. http://dx.doi.org/10.1080/10652460802106399

Love et al. (2003). Child care quality matters: How conclusions may vary with contetxt. Child Development, 74, 1021-1033. http://dx.doi.org/10.1111/1467-8624.00584

Maring, G. H., \& Magelky, J. (1990). Effective communication: Key to parent/community involvement. The Reading Teacher, 43(8), 606-607.

Mikkelsen, L., \& Chehimi, S. (2007). The links between the neighborhood food environment and childhood nutrition. Oakland, CA: Robert Wood Johnson Foundation.

Moore, H., Nelson, P., Marshall, J., Cooper, M., Zambas, H., Brewster, K., \& Atkin, K. (2005). Laying foundations for health: Food provision for under $5 \mathrm{~s}$ in day care. Appetite, 44(2), 407-413. http://dx.doi.org/ 10.1016/j.appet.2004.08.009

Morrongiello, B. A., Corbett, M., \& Bellissimo, A. (2008). "Do as I say, not as I do": Family influences on children's safety and risk behaviors. Health Psychology, 27(4), 498-503. http://dx.doi.org/10.1037/0278 $-6133.27 .4 .498$

National Childcare Accreditation Council. (2005). FDCQA Quality Practices Guide (3rd ed.). NCAC, Sydney, Australia.

NICHD Early Child Care Research Network. (2000). The relation of child care to cognitive and language development. Child Development, 71(4), 960-980. http://dx.doi.org/10.1111/1467-8624.00202

Olson, S. L., Bates, J. E., \& Bayles, K. (1984). Mother-infant interaction and the development of individual differences in children's cognitive competence. Developmental Psychology, 20(1), 166-179. http://dx.doi. org/10.1037/0012-1649.20.1.166

Owen, M. T., Ware, A. M., \& Barfoot, B. (2000). Caregiver-mother partnership behavior and the quality of caregiver-child and mother-child interactions. Early Childhood Research Quarterly, 15(3), 413-428. http://dx.doi.org/10.1016/S0885-2006(00)00073-9

Pagnini, D. L., Wilkenfeld, R. L., Ling, L. A., Booth, M. L., \& Booth, S. L. (2007). Early childhood sector staff perceptions of child overweight and obesity: The weight of opinion study. Health Promotion Journal of Australia, 18(2), 149-154.

Peisner-Feinberg, E. S., Burchinal, M. R., Clifford, R. M., Culkin, M. L. Howes, C., Kagan, S. L., \& Yazejian, N. (2001). The relation of preschool child-care quality to children's cognitive and social developmental 
trajectories through second grade. Child Development, 72(5), 1534-1553. http://dx.doi.org/10.1111/14678624.00364

QIAS. (2008). Quality Improvement and Accreditation System Quality Trends Report: For the period 1 January to 30 June 2008. National Childcare Accreditation Council Inc.

Rentzou, K. (2011). Parent-caregiver relationship dyad in Greek day care centers. International Journal of Early Years Education, 19(2), 163-177. http://dx.doi.org/10.1080/09669760.2011.609045

Sammons, P., Sylva, K., Edward, M., Siraj-Blatchford, I., Taggart, B., \& Elliot, K. (2002). Technical paper $8 a$ : Measuring the impact of preschool on children's cognitive progress over the pre-school period. London: University of London.

Scarr, S., Eisenberg, M., \& Deater-Deckard, K. (1994). Measurement of quality in child care centers. Early Research Childhood Quarterly, 9, 131-151. http://dx.doi.org/10.1016/0885-2006(94)90002-7

Shonkoff, J., \& Phillips, D. A. (Eds.). (n. d.). from neurons to neighborhoods: The science of early childhood development. Washington, DC: National Academy Press.

Sims, M., Guilfoyle, A., \& Parry, T. (2005). What cortisol levels tell us about quality in child care centers. Australian Jurnal of Early Childhood, 30(2), 29-39.

Sylva, K., Melhuish, E., Sammons, P., Siraj-Blatchford, I., Taggart, B., \& Elliot, K. (2003). The Effective Provision of Pre-School Education (EPPE) Project: Findings from the pre-school period. London, England: Institute of Education, University of London and SureStart.

Sylva, K., Siraj-Blatchford, I., Taggart, B., Melhuish, E., Elliot, K., \& Totsika, V. (2006). Capturing quality in early childhood through environmental ratings scales. Childhood Research Quarterly, 21, 76-92. $\mathrm{http}: / / \mathrm{dx}$.doi.org/10.1016/j.ecresq.2006.01.003

The National Health and Safety Performance Standards for Out-of-Home Child-care Programs Manual. (1992). American Public Health Association, Washington, D.C.; Nation. Center for Education in Maternal and Child Health, Washington, DC.

Vandell, D. (2004). Early child care: The known and the unknown. Merrill-Palmer Quarterly, 50, 387-414. http://dx.doi.org/10.1353/mpq.2004.0027

Wishard, A. G., Shivers, E. M., Howes, C., \& Ritchie, S. (2003). Child care program and teacher practices: Associations with quality and children's experiences. Early Childhood Research Quarterly, 18, 65-103. http://dx.doi.org/10.1016/S0885-2006(03)00007-3

\section{Copyrights}

Copyright for this article is retained by the author(s), with first publication rights granted to the journal.

This is an open-access article distributed under the terms and conditions of the Creative Commons Attribution license (http://creativecommons.org/licenses/by/3.0/). 